Research Article

\title{
Study on Identifying Significant Risk Sources during Bridge Construction Based on Grey Entropy Correlation Analysis Method
}

\author{
Kunpeng Wang, ${ }^{1}$ Chenggang $L u,{ }^{1}$ and Qingfu $L i \mathbb{D}^{2}$ \\ ${ }^{1}$ Powerchina Roadbridge Group Co, Ltd., Beijing 100048, China \\ ${ }^{2}$ School of Water Conservancy Engineering, Zhengzhou University, Zhengzhou 450001, China \\ Correspondence should be addressed to Qingfu Li; lqflch@zzu.edu.cn
}

Received 14 December 2020; Revised 10 February 2021; Accepted 20 February 2021; Published 4 March 2021

Academic Editor: Hui Wang

Copyright (c) 2021 Kunpeng Wang et al. This is an open access article distributed under the Creative Commons Attribution License, which permits unrestricted use, distribution, and reproduction in any medium, provided the original work is properly cited.

\begin{abstract}
Nowadays, many methods have been used in the identification of bridge risk sources, and certain results have been achieved. However, the research on the identification of significant risk sources of bridges during the construction period is relatively weak, and these methods still have some defects, such as the correlation between risk sources is not considered comprehensively, the dynamic risk sources are not fully considered, and the weight assignment is highly subjective. In order to solve these problems, this paper comprehensively uses the combination of expert scoring method, fuzzy analytic hierarchy process (F-AHP), and grey entropy correlation analysis (GECA) to identify significant risk sources during bridge construction. Firstly, the F-AHP and expert scoring method are used to initially identify safety sources during the bridge construction period, which effectively considers the identification of dynamic risk sources. Secondly, the combination of the GRA method and EW method is applied to identify the significant risk sources during bridge construction period, which can effectively analyze the interrelationship between different factors and greatly reduce the interference of subjective factors in the weight assignment, so as to effectively control the risks in construction and protect the health of the bridge structure and property losses. Finally, the feasibility and rationality of the proposed method were verified by comparing the AHP and GECA proposed in this paper in combination with specific engineering examples, which provides a reference basis for the identification of significant risk sources during the follow-up bridge construction period.
\end{abstract}

\section{Introduction}

With the needs of social development, bridge construction is developing in the direction of large spans and beautiful shapes, coupled with the widespread use of new materials and technologies, which inevitably poses a considerable challenge to today's bridge building technology. Due to the complex structural forms of the new bridge, unexpected safety accidents are inevitable despite the great care taken by staff during construction, so the risk sources during bridge construction should be identified, and the inherent correlation between the risk sources should be considered, the risks during bridge construction should be assessed, and reasonable improvement measures should be determined according to the excellence of the assessment results, to reduce the incidence of safety risk events to within acceptable limits and reduce all types of losses during bridge construction.

The construction process of large and complex bridges is complicated, the construction period is long, and there are many uncertain factors in the construction, the existence of a large number of risk factors threatens the smoothly of bridge construction all the time, and the interaction between various risk factors and the interrelationship between explicit and implicit factors have not been reasonably explained, so it is generally believed that every factor may have an impact on bridge construction. In fact, some factors will not cause too much damage to the bridge, and they are only caused by the progress of the bridge construction, if the same effort to treat each kind of risk factors, which is bound 
to consume a lot of human and material resources caused unnecessary waste. The key to distinguishing different types of risk factors is to analyze the interrelationship among them, to understand the mechanism of their development, to grasp the key factors, and to identify the significant sources of safety risks in bridge construction process [1], and with enough energy to treat it, which will get twice the result with half the effort and ensure the safety of the bridge construction process.

Risks are usually present in construction projects due to the occurrence of uncertain events, which are unavoidable and can lead to delays, increased costs and reduced quality of work [2]. The concept of "risk" and the systematic use of risk assessment methods to solve and deal with major decision problems in large bridge projects started in the early 1980's with the collision of ships and bridges [3]. Subsequently, risk identification was carried out in other areas, and in a case study of a 55-unit residential project in Cardiff, UK, Seyed [4] used Design Builder dynamic thermal simulation software to identify residential building risks at the initial design stage to assess the potential of thermal simulation software to identify potential risks at the early design stage. In order to systematically identify the risk sources affecting the operational safety of highway, Wu et al. [5] proposed a method to identify the operational safety risk sources of rocky high slopes based on the combination of basic site survey, geological condition survey, and quantitative monitoring and calculation, which can systematically and accurately identify the risk sources of rocky high slopes during the operational period and give specific index classification content, laying the foundation for the subsequent risk assessment. In order to identify the risk sources of ship pilotage, Liang et al. [6] comprehensively used the Delphi method for risk identification based on subjective information sources and prehazard analysis (PHA) for risk identification based on objective information sources for ship piloting risk source identification, which proposed a new method for ship pilotage risk identification. Ahmadi et al. [7] focused on the risk management of highway projects and took Iran's BijarZanjan highway as an example to use the fuzzy comprehensive evaluation method to carry out risk identification, risk assessment, and risk response and concluded that construction time, construction cost, and construction quality issues are the most important risk sources in highway construction. Although many scholars have promoted research on risk source identification in related fields, we found that these studies rarely identify risk sources during the construction period, which is not conducive to the overall research work on risk source identification.

Bridge risk identification methods usually include AHP (analytic hierarchy process), WBS-RBS (Work Breakdown Structure-Risk Breakdown Structure), and improved fuzzy analytic hierarchy process, and many scholars have also carried out related research. Saaty [8] first proposed a comprehensive risk identification method-AHP, which is used to identify risks such as bridge engineering, and later Bao et al. [9] and Wang et al. [10] really applied the method to bridge risk analysis and assessment, but it is difficult to make timely judgment for dynamic risk source identification and dynamic risk assessment by using this method alone. In order to prevent safety accidents in bridge construction in the marine environment, Wang et al. [11] combined hierarchical holographic modeling (HHM) and social network analysis (SNA) methods to identify significant sources of bridge safety risks and applied this method to the actual Tangshan Zhongshan Bridge project. The combined use of HHM and SNA was demonstrated through theoretical and case studies to be fully effective in identifying significant safety risk sources for bridge construction projects in the marine environment. Wang et al. [12] proposed a method for identifying safety risk factors in high-speed railway bridge construction based on literature research and typical case analysis, but the applicability of the method is insufficient for risk identification of complex bridges with high technical difficulty and little referable experience, such as extralarge and high-span bridges. Zhang et al. [13] took the construction of a high-pier and large-span bridge in a mountainous area as an example, through the analytic hierarchy process, identified its possible risk sources, and the results and conclusions of the analysis were consistent with the analysis conclusions of the causes of safety accidents in the bridge construction, verifying the feasibility of the method. However, this method is generally more complicated to calculate, and it greatly exerts human subjectivity in the process of weight determination. Ouyang et al. [14] combined the construction characteristics of continuous beam bridges, carried out research on the risk identification of bridge engineering construction, and proposed a comprehensive identification method for bridge construction risks that combines four methods: accident summary, structural analysis, field investigation, and expert investigation, and use examples to verify that it has strong practicability and effectiveness. In view of the large-area caisson structure, complex foundation soil characteristics and other factors that lead to outstanding risks in the construction of large bridge caisson foundations, Shi et al. [15] adopted the WBS-RBS (Work Breakdown Structure-Risk Breakdown Structure) method to identify the risks during the construction period of the caisson foundation of large bridges, then supplemented and adjusted risk sources based on expert survey opinions, and proposed targeted control countermeasures for risk sources. Zayed et al. [16] proposed a risk index $(R)$ to assess risk and prioritized bridges with unknown foundations. Primary risk parameters and their factors for bridges with unknown foundations were identified and analyzed and a model for calculating $R$ was designed. Li [17] proposed an improved analytic hierarchy process (AHP) based on entropy weight to identify risks during bridge construction. Li [18] proposed a risk identification method for bridge construction based on WBS-RBS (Work Breakdown Structure-Risk Breakdown Structure) and also proposed a coding system based on BCICS (Bridge Construction Information Classification System) and RBS to facilitate the risk of large bridges during the construction phase information is stored on a modular computer. Xiang [19] divided the design risks according to the basic life cycle of bridge design and obtained the risk sources in each design stage through the identification of design risks. Based on the 
analytic hierarchy process (AHP) and expert scoring, the weight of each index was established. However, above methods ignored the interaction and internal correlation between different risk sources, only considered the hazards caused by different risk sources separately, and did not consider the identification and control of significant risk sources.

Although many scholars have conducted a lot of research on the methods and applications of risk identification and have achieved many results, the research shows that the risks faced by structures such as bridge projects during the construction period are much higher than during the use period [20,21], and existing studies have few aspects of risk identification during construction of large and complex bridges, and the risk identification methods used are highly subjective, which is not conducive to reflecting the potential risk factors of the project itself, and failing to pay attention to the inherent relevance of different risk sources, it is difficult to truly identify significant sources of safety risks during bridge construction. GRA was proposed by Professor Deng Julong to measure the level of correlation between dynamic processes by analyzing their developmental dynamics and considering the intrinsic correlation of factors based on the calculated grey correlation between the comparison series and the reference series. The method is simple and intuitive to operate, with a small computational effort, and is nowadays widely used in the fields of risk assessment, wind power forecasting, and other fields [22, 23]. The concept of entropy was first proposed by Shannon in 1948 to represent a direction of development in nature, always moving from order to disorder. It represents a measure of uncertainty. Entropy can be used to measure the amount of information and extract valuable information from it. Nowadays, entropy is used to assign weight $[24,25]$ to ensure objectivity and accuracy. GECA is based on the introduction of the concept of EW on the basis of GCA. To this end, this paper organically combines the GCA and the concept of EW, introduces in detail the identification methods and processes of significant risk sources, analyzes the interaction and internal correlation between various risk sources, and ensures the accuracy and science of the identification work. By identifying the significant risk sources during the bridge construction period, we can effectively reduce the risky accidents during the construction process and improve the level of bridge construction safety risk management.

The main contributions of this paper are as follows:

(i) The expert scoring method and F-AHP method are applied to identify the initial risk sources during bridge construction period. Based on this method, dynamic risk source factors can be considered in real time, so that timely technical measures can be taken to cope with them. The interference of human factors in the subsequent risk assessment can be greatly reduced by this fuzzy method, and the accuracy of the assessment can be guaranteed.

(ii) A method of combining GCA method and EW is proposed to identify the significant risk sources during the construction period, and a GECA model is established to identify significant risk sources. The correlation between risk source factors is effectively considered, the weight of each index is objectively determined, and the interference of human subjectivity on risk identification is fully reduced.

(iii) The rationality and applicability of the GECA has been studied through actual engineering projects and compared to AHP, verified the feasibility of the method, and provided a reference for the identification of significant risk sources during the subsequent bridge construction period.

The rest of this paper is summarized as follows. Section 2 describes the methods and processes used in the preliminary identification of risk sources during bridge construction. Section 3 briefly describes the GECA model, including the methods and calculation steps involved. Section 4 uses an engineering case to carry out applied research and compares to AHP to verify the rationality of the method. Finally, the conclusions and future work are given in Section 5.

\section{Methods}

2.1. Identification of Risk Significant Sources during Bridge Construction. Various factors can threaten the safety of bridge structures during the bridge construction period, and due to the long construction period and complex procedures of the bridge, the risk sources in bridge construction are also relatively complex, and the risk sources that can directly or indirectly lead to a series of major safety accidents such as bridge collapse are now identified as significant risk sources. Identifying the significant risk sources during the construction period can control the risks in time and reduce losses. In order to effectively control the safety risks during the bridge construction period, we should first conduct a general survey of the overall risk sources during the bridge construction period and adopt a scientific method to determine its initial weight values [26], which provides a basis for the identification of significant risk sources. Significant risk source identification is mainly based on the risk survey work, assigning risk weights through risk census data combined with expert experience, and applies GECA to identify significant risk sources. Figure 1 shows the process of identifying significant risk sources during bridge construction.

2.1.1. Characteristics of the Risk Source Survey. Risk sources are the root causes of risk events, and in the process of risk analysis, clarifying the source of risk can play a vital role in the whole analysis process and analyze the results. In this paper, the expert scoring method is used to score the dynamic risk sources, then combines the F-AHP to determine the initial weights of the risk sources, and selects the risk sources through a combination of qualitative and quantitative methods to ensure the objectivity and risk assessment of risk source identification accuracy. The general survey of risk sources should have the following characteristics: 


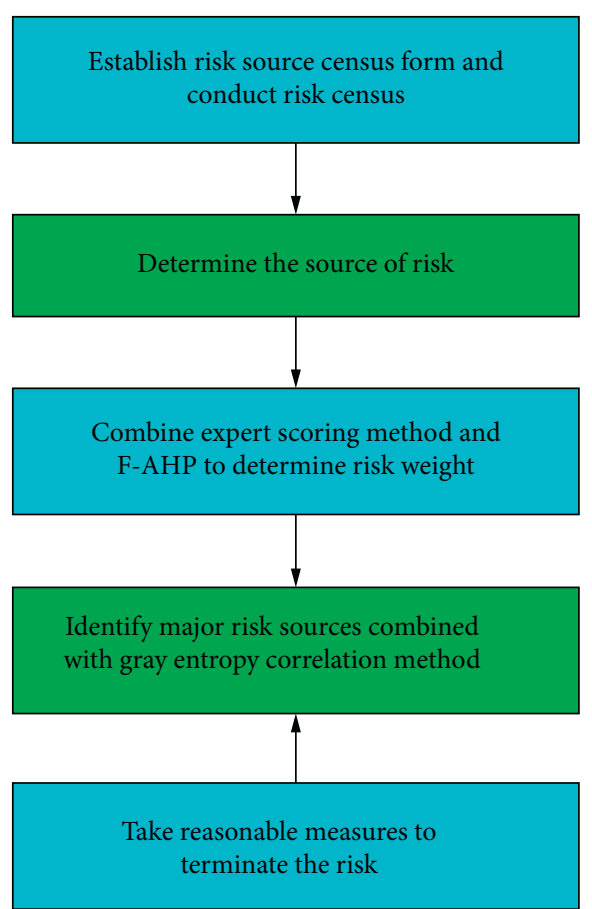

Figure 1: Process of identifying significant risk sources during bridge construction.

(1) Systematic. Risk sources exist in all aspects of bridge construction, which determine the systematic and comprehensiveness of the census process; that is, all safety risk events in the bridge construction process are caused by their corresponding risk sources, and all risk factors belong to the scope of the risk source census.

(2) Dynamic. The survey of risk sources is a dynamic and continuous process, and the process runs through the entire process of the bridge construction project. According to the characteristics of the project itself, a real-time general survey of risk sources in bridge construction is conducted and the risk database is updated, so that the risks can be evaluated in a timely manner and then a reasonable response plan can be made.

(3) Comprehensiveness. In the process of conducting a survey of risk sources, the concept of all-round and multilevel census should be followed, and all risk sources that directly or indirectly cause safety accidents should be taken into account to avoid missing relevant risk sources and causing safety risk accidents.

(4) Scientific. Process of risk source census should follow scientific statistical methods to ensure the authenticity of the census results, while also reducing blindness in the census process, and provide a basis for further risk quantification and the accuracy of risk assessment.

2.1.2. Risk Source Identification Process. According to the bridge construction procedures and characteristics, the risk source survey Table 1 is established, which consists of characterization characteristics such as risk source, consequences, and risk category. Through the preliminary evaluation of this table, preliminary statistics can be made on the risk sources during the bridge construction period, and then the risk source rights can be initially assigned by means of scoring by relevant experts in the industry [27].

According to the formation mechanism and characteristics of the risk, the risk sources were divided into design factors, mechanical factors, operating factors, environmental factors, material factors, and management factors. Similarly, the expert scoring method is used to assign weights to each risk source, and then the scores are normalized to obtain $T_{j}[28]$.

2.1.3. Determining Initial Weights. The method of expert scoring combined with the F-AHP method is used to initially assign the identified risk sources. This method first establishes a hierarchical structure framework for the decisionmaking system [29], constructs a fuzzy evaluation matrix, and then performs fuzzy consistency judgment. F-AHP is more complete and applicable than AHP, the method is simple to operate, and it greatly reduces the interference of human factors on the data [30]:

(1) Establish a hierarchical structure framework Assuming that the evaluation object has $n$ risk factors, the risk factor set is expressed as $\left(u_{1}, u_{2}, \ldots, u_{n}\right)$ and establishes a priority relationship judgment matrix [31]:

$$
r=\left[\begin{array}{cccc}
r_{11} & r_{12} & \ldots & r_{1 n} \\
r_{21} & r_{22} & \ldots & r_{2 n} \\
\ldots & \ldots & \ldots & \ldots \\
r_{n 1} & r_{n 2} & \ldots & r_{n n}
\end{array}\right] .
$$

The value of $r_{i j}$ refers to

$$
r_{i j}= \begin{cases}0.5, & t(i)=t(j), \\ 1, & t(i)>t(j), \quad i, j=1,2, \ldots, n . \\ 0, & t(i)<t(j) .\end{cases}
$$

Among them, $t(i)$ and $t(j)$ represent the relative importance of $u(i)$ and $u(j)$, respectively.

(2) Consistency judgment

From the matrix $R$, the fuzzy consistent judgment matrix $R$ can be established:

$$
R_{i j}=\left[\begin{array}{cccc}
R_{11} & R_{12} & \ldots & R_{1 n} \\
R_{21} & R_{22} & \ldots & R_{2 n} \\
\vdots & \vdots & \vdots & \vdots \\
R_{n 1} & R_{n 2} & \ldots & R_{n n}
\end{array}\right],
$$

where $R_{i j}=\left(\left(k_{i}-k_{j}\right) / 2 n\right)+0.5$. Among them, $k_{i}=\sum_{j=1}^{n} r_{i j}, i=1,2, \ldots, n$. Element $R_{i j}$ in fuzzy consistent matrix indicates the importance of the $i$ element and element $j$ in $\left\{u_{1}, u_{2}, \ldots, u_{n}\right\}$. 
TABLE 1: General survey of risk sources during bridge construction.

\begin{tabular}{|c|c|c|c|c|c|c|}
\hline Process & Risk source & Consequences & Risk category & Severity & Safe or dangerous & Remarks \\
\hline 1 & 1 & & & & $\sqrt{ }$ & \\
\hline 2 & 2 & & & & $\sqrt{ }$ & \\
\hline$\ldots$ & $\begin{array}{l}\ldots \\
M\end{array}$ & $\ldots$ & $\ldots$ & $\ldots$ & $\begin{array}{l}\ldots \\
x\end{array}$ & $\ldots$ \\
\hline \multicolumn{2}{|c|}{ Filler: } & \multicolumn{2}{|c|}{ Proofreader: } & & Date of filling: & \\
\hline
\end{tabular}

(1) $0 \leq R_{i j}<0.5$, the smaller $R_{i j}$ is, the more important $u_{j}$ is than $u_{i}$

(2) $R_{i j}=0.5$, indicates that $u_{j}$ and $u_{i}$ are equally important

(3) $0.5<R_{i j} \leq 1$, the smaller $R_{i j}$ is, the more important $u_{i}$ is than $u_{j}$

(3) Determine the relative weight

(1) First, the fuzzy consistent judgment matrix Ris normalized by a column to obtain the matrix $B$ :

$$
b_{i j}=\frac{R_{i j}}{\sum_{i=1}^{n} R_{i j}}, \quad i, j=1,2, \ldots, n .
$$

(2) Adding the elements in matrix $B$ row by row to get vector $C$ :

$$
c_{i}=\sum_{j=1}^{n} b_{i j}, \quad i, j=1,2, \ldots n .
$$

(3) The vector $C$ is normalized to obtain the relative weight $W$ :

$$
w_{i}=\frac{c_{i}}{\sum_{k=1}^{n} c_{k}}, \quad i=1,2, \ldots, n .
$$

(4) Multiply the relative weight of each classification coefficient to obtain the relative weight coefficient matrix $V$ of risk sources:

$$
V_{i j}=w_{i} \times t_{j}, \quad j=1,2, \ldots, 6 .
$$

\section{Grey Entropy Association Analysis Model}

The development process of things can be seen as a complex system, and the various factors of the system develop over time. The basic idea of GECA is to judge the correlation based on the similarity of the geometric shape of the sequence of factors. That is, analyze the changes of the sequence over time and judge the correlation between them according to the magnitude, direction, and speed of the sequence of changes [32], the GECA can reasonably judge the interrelationship of various factors based on the developmental characteristics of things, and it has good performance in the application of bridge construction systems $[33,34]$.

3.1. The Basic Steps of GRA. Before calculation, determine the reference sequence. Reference sequence $X_{0}^{\prime}(t)$ should be an ideal comparison standard, can be the best value (or the worst value) of each indicator to form a reference data column, or can choose other reference values according to the purpose of evaluation, noted as

$$
x_{0}^{\prime}(t)=\left\{x_{0}^{\prime}(1), x_{0}^{\prime}(2), \ldots, x_{0}^{\prime}(n)\right\} .
$$

(1) Find the initial value

There are differences in the dimension of each indicator data, and in order to facilitate data calculation and make the series comparable with each other, it is necessary to process the data and unify the dimension [35]. Make

$x_{i}^{\prime}(k)=\frac{x_{i}(k)}{x_{i}(1)}, \quad i=0,1,2, \ldots, n ; k=1,2, \ldots, m$.

Among them, $x_{i}(k)$ is the comparison sequence value.

(2) Evaluation of sequence of difference

Calculate the absolute value of each reference sequence and comparison sequence $\Delta_{i}(k)$, which is

$$
\begin{aligned}
\Delta_{i}(k) & =\left|x_{0}^{\prime}(k)-x_{i}^{\prime}(k)\right|, \\
\Delta_{i} & =\left(\Delta_{i}(1), \Delta_{i}(1), \ldots, \Delta_{i}(n)\right), \quad i=0,1,2, \ldots, m .
\end{aligned}
$$

(3) Find the maximum difference and the minimum difference between the two levels:

$$
\begin{aligned}
M & =\max _{i} \max _{k} \Delta_{i}(k), \\
m & =\min _{i} \min _{k} \Delta_{i}(k) .
\end{aligned}
$$

(4) Find the correlation coefficient, that is, the degree of correlation between the reference sequence and the comparison sequence:

$$
\xi_{i}(k)=\frac{\Delta_{\min }+\rho \cdot \Delta_{\max }}{\Delta_{i}(k)+\rho \cdot \Delta_{\max }},
$$

where $\rho$ is the resolution coefficient, $\rho \in[0,1]$, under normal circumstances, $\rho$ takes $0.5, k=1,2, \ldots, m$, $i=1,2, \ldots, n$.

(5) Establish the grey incidence matrix $\xi$ :

$$
\xi=\left(\xi_{i j}\right)_{m \times n}=\left[\begin{array}{cccc}
\xi_{11} & \xi_{12} & \ldots & \xi_{1 n} \\
\xi_{21} & \xi_{22} & \ldots & \xi_{2 n} \\
\ldots & \ldots & \ldots & \ldots \\
\xi_{m 1} & \xi_{m 2} & \ldots & \xi_{m n}
\end{array}\right],
$$

where $\xi$ is the correlation coefficient. 
3.2. The Basic Steps of EW. Entropy represents a direction of development in nature, which always develops from order to disorder, that is, from a small number of microscopic states to a large number of microscopic states [36]. In the process of identifying significant risk sources during bridge construction, the application of entropy for weight assignment can improve the accuracy of the evaluation system [37]:

(1) Entropy method to determine the index weight Under the $j$-the index, the proportion of thei-the index value is

$$
P_{i j}=\frac{Y_{i j}}{\sum_{i=1}^{m} Y_{i j}},
$$

where $Y_{i j}$ is the normalized value of the $j$-th index under the $i$-th index, and $Y_{i j} \in[0,1], \sum_{i=1}^{m} Y_{i j}>0$.

(2) Calculate the information entropy, and the information entropy of the $j$-the index is

$$
e_{j}=-k \sum_{i=1}^{m} P_{i j} \ln P_{i j},
$$

where $k>0, e_{j}>0, k=(1 / \ln m) . m$ is a constant, so $k$ will also be a constant.

(3) Determine the weight $w_{j}$ :

$$
w_{j}=\frac{\left(1-e_{j}\right)}{\sum_{j=1}^{n}\left(1-e_{j}\right)},
$$

where $w_{j}$ represents the weighting factor of the $j$-th index.

3.3. Grey Entropy Association Analysis. GECA is based on the introduction of the concept of EW on the basis of GCA, combine the two methods organically, and obtain the correlation degree between the $i$-the index and $j$ subsequences:

$$
\beta_{i}=\sum_{j=1}^{n} \xi_{i j} w_{j} .
$$

The correlation degree values that have been calculated are ranked, and the sequences with higher correlation degree may have greater risk, the indicators with high correlation are defined as significant risk factors, and this method is used as the judgment criterion for significant risk source identification.

\section{Engineering Applications}

Taking the pile foundation construction of the Yinzhou Lake Bridge as an example, F-AHP, GRA method, and EW are used to identify the significant risk sources in the construction of pile foundation and describe the significant risk sources quantitatively and qualitatively.

4.1. Identifying and Quantifying Risk Sources. According to the construction steps of the pile foundation of Yinzhou
Lake Bridge, the F-AHP was used for preliminary risk source identification. Firstly, follow the principles of dynamic, scientific, comprehensive, and systematic to establish a risk survey form, according to site conditions, actual data, site inquiries, and expert opinions, conduct a general survey and classification of risk sources during the construction period of the pile foundation in the bridge substructure, and conduct preliminary identification of risk sources. 15 experts of related professions were selected and combined with previous engineering experience to score the proportion of each factor in each risk source, and finally processed the data through normalization. The risk events to determine the pile foundation project include equipment transportation and installation, burying of protective cylinders, drilling holes, cleaning hole, lifting of steel cages, and pouring underwater concrete. Each risk event contains multiple risk sources. The risk events and sources are shown in Table 2, and the risk survey results are shown in Table 3 . A preliminary assessment of the safety risks during the construction of the pile foundation of the Yinzhou Lake Bridge was carried out according to the "Guidelines for the Safety Risk Assessment of Highway Bridge and Tunnel Engineering Construction" [38]. Among them, $\mathrm{A}$ is the pile foundation construction project, $\mathrm{B}$ is the risk event, and $\mathrm{C}$ is the risk source.

(1) Taking pile foundation construction A as an example, first establish the priority A-B relationship matrix and fuzzy consistency matrix, use formulas (1)-(6) to calculate, and the results are shown in Tables 4 and 5 .

(2) Referring to the methods in Tables 4 and 5, then establish the priority relationship matrix of risk sources and risk events in the pile foundation construction stage, and through the same calculation method, the relationship matrix and fuzzy consistency matrix of 6 categories B-C are derived, which are not listed here, and the relative weight values of the obtained B-C fuzzy consistency matrix are shown in Table 6, and the preliminary weight values of risk sources (C) relative to the pile foundation construction stage $(\mathrm{A})$ are obtained.

(3) The influence of design factors, mechanical factors, operating error factors, environmental factors, material factors, and management factors on each risk source was determined by means of the expert scoring method. Combining the preliminary weight values of each risk source calculated above and the score value of the risk source classification, the initial value image of each risk source is determined, see Table 7 for details.

4.2. Grey Entropy Association Analysis. Combining the types and weights of risk sources that have been initially determined, the GECA is used to determine the correlation between various factors, so as to find the most unfavorable construction safety risk factors and carry out effective prevention and control management.

(1) Combine the preliminary weight value of each risk source calculated above and the score value of the 
TABLE 2: Risk events and sources of pile foundation construction of the Yinzhou Lake Bridge.

\begin{tabular}{|c|c|c|}
\hline Engineering & Risk event & Risk source \\
\hline $\begin{array}{l}\mathrm{A}_{1} \text { : pile foundation } \\
\text { construction }\end{array}$ & $\mathrm{B}_{2}$ : burying of protective cylinders & 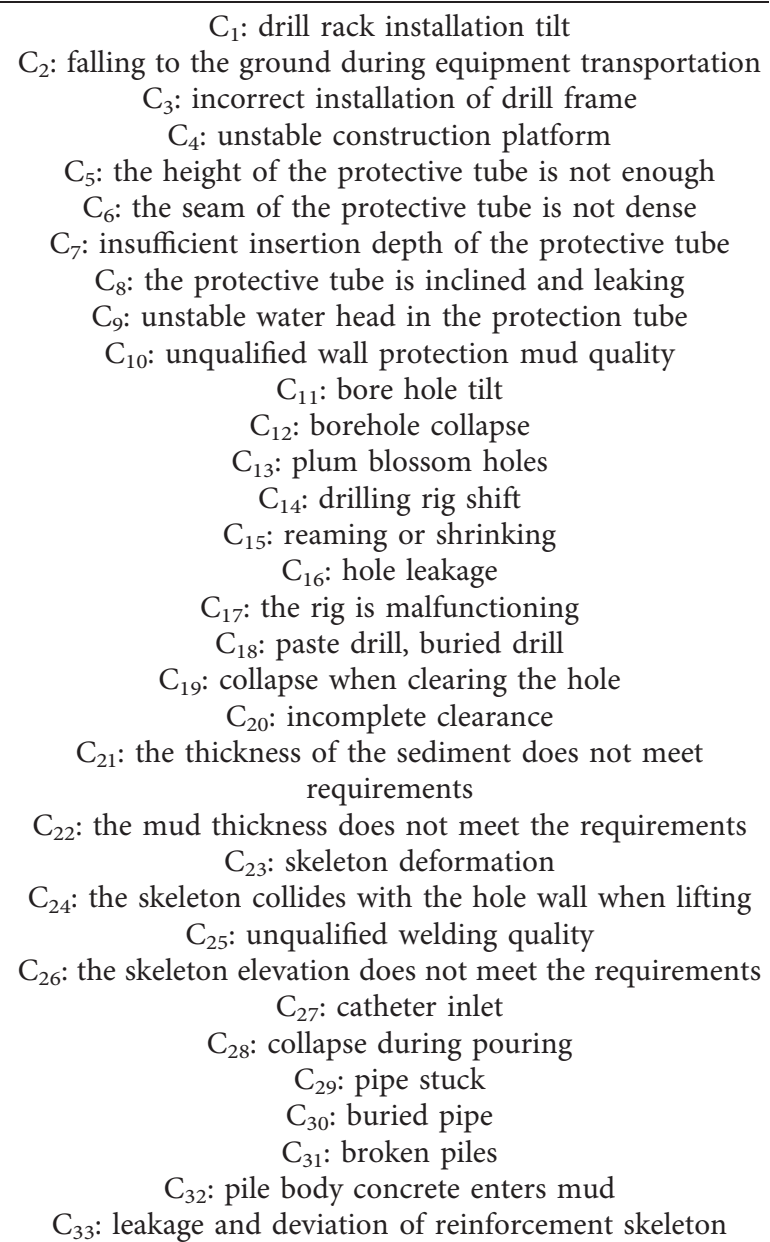 \\
\hline
\end{tabular}

risk source classification to determine the initial value image of each risk source, and extract the maximum value of various risks from the identified risk sources as the most unfavorable factor of this type of risk; define the vector $X_{0}$ as the most dangerous value, which is used as the reference sequence for this type of risk:

$$
X_{0}=\left[\begin{array}{llllll}
1.782 & 0.920 & 2.104 & 0.434 & 1.527 & 1.578
\end{array}\right] .
$$

(2) Using formulas (8)-(14) to normalize the initial value image, and then find the difference sequence and correlation coefficient to establish the correlation coefficient matrix. Using the grey entropy correlation algorithm to sort the sequence to find the major risk sources, the correlation coefficient matrix is shown in Table 8.

(3) Determine the weight $w_{j}$

According to formulas (15)-(17), using the EW and the initial image data in Table 7 to determine the weight of each index, the weight coefficient $w_{j}$ of various factors in the pile foundation construction of the Yinzhou Lake Bridge is calculated:

$$
w_{j}=\left[\begin{array}{llllll}
0.181 & 0.136 & 0.274 & 0.051 & 0.153 & 0.205
\end{array}\right] .
$$

(4) Determine the weight of evaluation indicators.

Apply the correlation coefficient matrix $w_{j}$ in Table 8 multiplied by the weight coefficients of various factors in the pile foundation construction of the Yinzhou Lake Bridge to obtain the magnitude of the safety risk indicators in the pile foundation construction and sort the indicators to filter out significant risk sources: $\beta_{j}=\left[\begin{array}{lllll}0.787 & 0.601 & 0.459 & 0.712 & 0.542\end{array}\right.$ $\begin{array}{llllllllllllll}0.454 & 0.737 & 0.659 & 0.735 & 0.725 & 0.728 & 0.755 & 0.623 & 0.623 & 0.546\end{array}$ $\begin{array}{llllllllllll}0.673 & 0.702 & 0.565 & 0.481 & 0.481 & 0.481 & 0.677 & 0.509 & 0.451 & 0.608\end{array}$ $\left.\begin{array}{llllllll}0.575 & 0.453 & 0.728 & 0.625 & 0.484 & 0.640 & 0.640 & 0.645\end{array}\right]^{T}$.

4.3. Result Analysis. The weights of risk sources were calculated by GECA, and the risk sources in the process of pile foundation construction were ranked in the following order: $\mathrm{C}_{1}, \mathrm{C}_{12}, \mathrm{C}_{7}, \mathrm{C}_{9}, \mathrm{C}_{11}, \mathrm{C}_{28}, \mathrm{C}_{10}, \mathrm{C}_{4}, \mathrm{C}_{17}, \mathrm{C}_{22}, \mathrm{C}_{16}, \mathrm{C}_{8}, \mathrm{C}_{33}, \mathrm{C}_{31}$, $\mathrm{C}_{32}, \mathrm{C}_{29}, \mathrm{C}_{13}, \mathrm{C}_{14}, \mathrm{C}_{25}, \mathrm{C}_{2}, \mathrm{C}_{26}, \mathrm{C}_{18}, \mathrm{C}_{15}, \mathrm{C}_{5}, \mathrm{C}_{23}, \mathrm{C}_{30}, \mathrm{C}_{19}$, 
TABLE 3: General survey table of construction safety risks of the Yinzhou Lake Bridge.

\begin{tabular}{|c|c|c|c|c|c|c|c|c|}
\hline \multirow{2}{*}{ Construction stage } & \multirow{2}{*}{ Risk event } & \multirow{2}{*}{ Risk source } & \multicolumn{6}{|c|}{ Risk source type (100\%) } \\
\hline & & & Design & Mechanical & Operating & Environment & Material & Management \\
\hline \multirow{33}{*}{$A_{1}$} & \multirow{4}{*}{$\mathrm{B}_{1}$} & $\mathrm{C}_{1}$ & 15 & 20 & 15 & 15 & 30 & 5 \\
\hline & & $\mathrm{C}_{2}$ & 20 & 10 & 30 & 5 & 15 & 20 \\
\hline & & $\mathrm{C}_{3}$ & 5 & 20 & 40 & 5 & 5 & 25 \\
\hline & & $\mathrm{C}_{4}$ & 79 & 5 & 5 & 1 & 5 & 5 \\
\hline & \multirow{5}{*}{$\mathrm{B}_{2}$} & $\mathrm{C}_{5}$ & 10 & 10 & 38 & 2 & 38 & 2 \\
\hline & & $\mathrm{C}_{6}$ & 40 & 5 & 40 & 5 & 5 & 5 \\
\hline & & $\mathrm{C}_{7}$ & 28 & 2 & 28 & 2 & 20 & 20 \\
\hline & & $\mathrm{C}_{8}$ & 28 & 2 & 25 & 2 & 20 & 23 \\
\hline & & $\mathrm{C}_{9}$ & 10 & 46 & 30 & 2 & 10 & 2 \\
\hline & \multirow{9}{*}{$\mathrm{B}_{3}$} & $\mathrm{C}_{10}$ & 10 & 38 & 28 & 2 & 2 & 20 \\
\hline & & $\mathrm{C}_{11}$ & 20 & 2 & 28 & 2 & 38 & 10 \\
\hline & & $\mathrm{C}_{12}$ & 10 & 2 & 20 & 10 & 28 & 30 \\
\hline & & $\mathrm{C}_{13}$ & 10 & 20 & 30 & 10 & 10 & 20 \\
\hline & & $\mathrm{C}_{14}$ & 10 & 20 & 30 & 10 & 10 & 20 \\
\hline & & $\mathrm{C}_{15}$ & 15 & 5 & 30 & 5 & 30 & 15 \\
\hline & & $\mathrm{C}_{16}$ & 10 & 30 & 20 & 10 & 10 & 20 \\
\hline & & $\mathrm{C}_{17}$ & 10 & 15 & 35 & 10 & 2 & 28 \\
\hline & & $\mathrm{C}_{18}$ & 5 & 20 & 43 & 2 & 2 & 28 \\
\hline & \multirow{4}{*}{$\mathrm{B}_{4}$} & $\mathrm{C}_{19}$ & 10 & 10 & 40 & 5 & 5 & 30 \\
\hline & & $\mathrm{C}_{20}$ & 10 & 10 & 40 & 5 & 5 & 30 \\
\hline & & $\mathrm{C}_{21}$ & 10 & 10 & 40 & 5 & 5 & 30 \\
\hline & & $\mathrm{C}_{22}$ & 5 & 10 & 33 & 2 & 30 & 20 \\
\hline & \multirow{4}{*}{$\mathrm{B}_{5}$} & $\mathrm{C}_{23}$ & 5 & 15 & 45 & 5 & 5 & 25 \\
\hline & & $\mathrm{C}_{24}$ & 10 & 5 & 40 & 5 & 30 & 10 \\
\hline & & $\mathrm{C}_{25}$ & 35 & 10 & 15 & 5 & 20 & 15 \\
\hline & & $\mathrm{C}_{26}$ & 30 & 5 & 15 & 2 & 28 & 20 \\
\hline & \multirow{7}{*}{$\mathrm{B}_{6}$} & $\mathrm{C}_{27}$ & 10 & 5 & 40 & 5 & 10 & 30 \\
\hline & & $\mathrm{C}_{28}$ & 20 & 10 & 25 & 5 & 10 & 30 \\
\hline & & $\mathrm{C}_{29}$ & 15 & 10 & 40 & 5 & 10 & 20 \\
\hline & & $\mathrm{C}_{30}$ & 20 & 15 & 30 & 5 & 15 & 15 \\
\hline & & $\mathrm{C}_{31}$ & 25 & 10 & 35 & 10 & 5 & 15 \\
\hline & & $\mathrm{C}_{32}$ & 25 & 10 & 35 & 10 & 5 & 15 \\
\hline & & $\mathrm{C}_{33}$ & 20 & 5 & 40 & 10 & 20 & 5 \\
\hline
\end{tabular}

TABLE 4: A-B relationship matrix.

\begin{tabular}{ccccccc}
\hline $\mathrm{A}$ & $\mathrm{B}_{1}$ & $\mathrm{~B}_{2}$ & $\mathrm{~B}_{3}$ & $\mathrm{~B}_{4}$ & $\mathrm{~B}_{5}$ & \\
\hline $\mathrm{B}_{1}$ & 0.5 & 0 & 0 & 1 & 0 & $\mathrm{~B}_{6}$ \\
$\mathrm{~B}_{2}$ & 1 & 0.5 & 0 & 0 & 0 & 0 \\
$\mathrm{~B}_{3}$ & 1 & 1 & 0.5 & 1 & 0 & 0 \\
$\mathrm{~B}_{4}$ & 0 & 1 & 0 & 0.5 & 0 & 0 \\
$\mathrm{~B}_{5}$ & 1 & 1 & 0 & 1 & 0.5 & 0 \\
$\mathrm{~B}_{6}$ & 1 & 1 & 1 & 1 & 0.5 \\
\hline
\end{tabular}

TABle 5: A-B fuzzy consistent matrix $R$ and relative weight value $w_{A}^{B}$.

\begin{tabular}{cccccccc}
\hline $\mathrm{A}$ & $\mathrm{B}_{1}$ & $\mathrm{~B}_{2}$ & $\mathrm{~B}_{3}$ & $\mathrm{~B}_{4}$ & $\mathrm{~B}_{5}$ & $\mathrm{~B}_{6}$ & Relative weight $w_{A}^{B}$ \\
\hline $\mathrm{B}_{1}$ & 0.500 & 0.500 & 0.250 & 0.500 & 0.333 & 0.167 & 0.121 \\
$\mathrm{~B}_{2}$ & 0.500 & 0.500 & 0.250 & 0.500 & 0.333 & 0.167 & 0.121 \\
$\mathrm{~B}_{3}$ & 0.750 & 0.750 & 0.500 & 0.750 & 0.583 & 0.417 & 0.212 \\
$\mathrm{~B}_{4}$ & 0.500 & 0.500 & 0.250 & 0.500 & 0.333 & 0.167 & 0.121 \\
$\mathrm{~B}_{5}$ & 0.667 & 0.667 & 0.417 & 0.667 & 0.500 & 0.333 & 0.242 \\
$\mathrm{~B}_{6}$ & 0.833 & 0.833 & 0.583 & 0.833 & 0.667 & 0.500 & \\
\hline
\end{tabular}


TABLE 6: Total ranking results of the hierarchy.

\begin{tabular}{|c|c|c|c|c|c|c|c|}
\hline \multirow{2}{*}{$\begin{array}{l}\text { Level } \\
\text { C }\end{array}$} & \multicolumn{6}{|c|}{ Single weight $w_{B}^{C}$} & \multirow{2}{*}{$\begin{array}{c}\text { Weight value } \\
w_{A}^{C}\end{array}$} \\
\hline & $\begin{array}{c}\mathrm{B}_{1} \\
0.121\end{array}$ & $\begin{array}{c}\mathrm{B}_{2} \\
0.121\end{array}$ & $\begin{array}{c}\mathrm{B}_{3} \\
0.212\end{array}$ & $\begin{array}{c}\mathrm{B}_{4} \\
0.121\end{array}$ & $\begin{array}{c}\mathrm{B}_{5} \\
0.182\end{array}$ & $\begin{array}{c}\mathrm{B}_{6} \\
0.242\end{array}$ & \\
\hline $\mathrm{C}_{1}$ & 0.281 & & & & & & 0.0341 \\
\hline $\mathrm{C}_{2}$ & 0.281 & & & & & & 0.0341 \\
\hline $\mathrm{C}_{3}$ & 0.219 & & & & & & 0.0266 \\
\hline $\mathrm{C}_{4}$ & 0.219 & & & & & & 0.0266 \\
\hline $\mathrm{C}_{5}$ & & 0.24 & & & & & 0.0291 \\
\hline $\mathrm{C}_{6}$ & & 0.12 & & & & & 0.0146 \\
\hline $\mathrm{C}_{7}$ & & 0.28 & & & & & 0.0340 \\
\hline $\mathrm{C}_{8}$ & & 0.2 & & & & & 0.0243 \\
\hline $\mathrm{C}_{9}$ & & 0.16 & & & & & 0.0194 \\
\hline $\mathrm{C}_{10}$ & & & 0.086 & & & & 0.0182 \\
\hline $\mathrm{C}_{11}$ & & & 0.111 & & & & 0.0235 \\
\hline $\mathrm{C}_{12}$ & & & 0.074 & & & & 0.0157 \\
\hline $\mathrm{C}_{13}$ & & & 0.160 & & & & 0.0339 \\
\hline $\mathrm{C}_{14}$ & & & 0.148 & & & & 0.0314 \\
\hline $\mathrm{C}_{15}$ & & & 0.123 & & & & 0.0261 \\
\hline $\mathrm{C}_{16}$ & & & 0.062 & & & & 0.0131 \\
\hline $\mathrm{C}_{17}$ & & & 0.136 & & & & 0.0288 \\
\hline $\mathrm{C}_{18}$ & & & 0.099 & & & & 0.0210 \\
\hline $\mathrm{C}_{19}$ & & & & 0.343 & & & 0.0416 \\
\hline $\mathrm{C}_{20}$ & & & & 0.219 & & & 0.0266 \\
\hline $\mathrm{C}_{21}$ & & & & 0.219 & & & 0.0266 \\
\hline $\mathrm{C}_{22}$ & & & & 0.219 & & & 0.0266 \\
\hline $\mathrm{C}_{23}$ & & & & & 0.219 & & 0.0398 \\
\hline $\mathrm{C}_{24}$ & & & & & 0.281 & & 0.0511 \\
\hline $\mathrm{C}_{25}$ & & & & & 0.281 & & 0.0511 \\
\hline $\mathrm{C}_{26}$ & & & & & 0.219 & & 0.0398 \\
\hline $\mathrm{C}_{27}$ & & & & & & 0.102 & 0.0247 \\
\hline $\mathrm{C}_{28}$ & & & & & & 0.082 & 0.0199 \\
\hline $\mathrm{C}_{29}$ & & & & & & 0.204 & 0.0494 \\
\hline $\mathrm{C}_{30}$ & & & & & & 0.122 & 0.0296 \\
\hline $\mathrm{C}_{31}$ & & & & & & 0.184 & 0.0446 \\
\hline $\mathrm{C}_{32}$ & & & & & & 0.143 & 0.0346 \\
\hline $\mathrm{C}_{33}$ & & & & & & 0.163 & 0.0395 \\
\hline
\end{tabular}

$\mathrm{C}_{20}, \mathrm{C}_{21}, \mathrm{C}_{3}, \mathrm{C}_{6}, \mathrm{C}_{27}, \mathrm{C}_{24}$. According to the results of risk sources ranking, the significant risk sources in the process of pile foundation construction of the Yinzhou Lake Bridge can be identified, and the risks can be eliminated in a targeted manner. By sorting the results, the significant risk sources in the pile foundation construction process are drill rack installation tilt $\left(\mathrm{C}_{1}\right)$, borehole collapse $\left(\mathrm{C}_{12}\right)$, insufficient insertion depth of the protective tube $\left(C_{7}\right)$, unstable water head in the protection tube $\left(\mathrm{C}_{9}\right)$, bore hole tilt $\left(\mathrm{C}_{11}\right)$, collapse during pouring $\left(\mathrm{C}_{28}\right)$, unqualified wall protection mud quality $\left(\mathrm{C}_{10}\right)$, unstable construction platform $\left(\mathrm{C}_{4}\right)$, etc., which need to be prevented in advance during the construction process, and do a good job of safety plan demonstration work, and the personnel operation and site management during the construction process must be sufficiently cautious to ensure the safety of the bridge structure and personnel, to guarantee the construction progress and construction quality.

4.4. Comparison Study. At present, the most used method for risk source identification is the AHP method [13, 39, 40], and we have adopted this method as a comparative study. The main steps of the AHP method are as follows: establish a hierarchical structure model, construct all the judgment matrices in each level, and use the two-by-two comparison method to obtain the weight of a single influencing factor and ranking the weight of each influencing factor.

4.4.1. Building a Hierarchical Structure Model. Divide the decision-making goals, consideration factors, and decision objects into the highest, middle, and lowest levels according to their mutual relationship, and draw a hierarchical structure diagram. The highest level refers to the purpose of decision-making and the problem to be solved; the lowest level refers to the alternatives when making a decision; the middle level refers to the factors considered and the criteria for decision-making. Combining with the engineering practice, according to the site situation, actual information, and expert opinions, it was determined that the risk events of the pile foundation project of the Yinzhou Lake Bridge include equipment transportation and installation, burying of protective cylinders, drilling holes, cleaning hole, lifting of steel cages, and pouring underwater concrete, each risk event contains multiple risk sources, and finally, a three-layer hierarchical model containing the target layer, the criterion layer, and the indicator layer is established. As shown in Figure $2, B_{1}, B_{2}, \ldots, B_{6}$ and $C_{1}, C_{2}, \ldots, C_{33}$ refer to risk events and risk sources, respectively, and the specific content is the same as that in Table 2.

4.4.2. Constructing the Judgment Matrix at Each Level. According to the established hierarchical structure analysis model, experienced experts are asked to compare and score each risk factor by the method of two-by-two comparison. The relative importance of the two factors is usually compared using a proportional scale table, as shown in Table 9, after scoring by experts, the constructed criterion-level risk event relative to the target-level judgment matrix is shown in Table 10.

The square root method is used to calculate the weight of each factor. Firstly, the product of each row of elements is found, and after the product of each row of elements is obtained, then take the 6th root of the product of each row, and then divide the value of the 6 th root of each row by the sum of the square roots to find the obtained 6 quotients constitute the 6 elements of the weight eigenvector of the judgment matrix, which is the weight eigenvector. In this example, the weight eigenvector is $[0.094,0.03,0.267,0.048,0.136,0.425]^{T}$. The matrix operation is performed by multiplying the judgment matrix with the eigenvector, and the maximum eigenvalue is obtained according to the following formula:

$$
\lambda_{\max }=\sum_{i=1}^{n} \frac{(A W)_{i}}{n W_{i}},
$$

where $A$ is the judgment matrix, $W$ is the eigenvector, and $n$ is the number of elements. In this case, the maximum eigenvalue is 6.605 . 
TABLE 7: Initial image of risk sources in construction of the Yinzhou Lake Bridge.

\begin{tabular}{|c|c|c|c|c|c|c|c|c|}
\hline Engineering & Risk event & Risk source & Design & Mechanical & Operating & Environment & Material & Management \\
\hline \multirow{33}{*}{$\mathrm{A}_{1}$} & \multirow{4}{*}{$\mathrm{B}_{1}$} & $\mathrm{C}_{1}$ & 0.409 & 0.546 & 0.409 & 0.409 & 0.818 & 0.136 \\
\hline & & $\mathrm{C}_{2}$ & 0.546 & 0.273 & 0.818 & 0.136 & 0.409 & 0.546 \\
\hline & & $\mathrm{C}_{3}$ & 0.106 & 0.424 & 0.849 & 0.106 & 0.106 & 0.531 \\
\hline & & $\mathrm{C}_{4}$ & 1.676 & 0.106 & 0.106 & 0.021 & 0.106 & 0.106 \\
\hline & \multirow{5}{*}{$\mathrm{B}_{2}$} & $\mathrm{C}_{5}$ & 0.300 & 0.300 & 1.140 & 0.060 & 1.140 & 0.060 \\
\hline & & $\mathrm{C}_{6}$ & 0.600 & 0.075 & 0.600 & 0.075 & 0.075 & 0.075 \\
\hline & & $\mathrm{C}_{7}$ & 0.980 & 0.070 & 0.980 & 0.070 & 0.700 & 0.700 \\
\hline & & $\mathrm{C}_{8}$ & 0.700 & 0.050 & 0.625 & 0.050 & 0.500 & 0.575 \\
\hline & & $\mathrm{C}_{9}$ & 0.200 & 0.920 & 0.600 & 0.040 & 0.200 & 0.040 \\
\hline & \multirow{9}{*}{$\mathrm{B}_{3}$} & $\mathrm{C}_{10}$ & 0.180 & 0.683 & 0.503 & 0.036 & 0.036 & 0.360 \\
\hline & & $\mathrm{C}_{11}$ & 0.462 & 0.046 & 0.647 & 0.046 & 0.878 & 0.231 \\
\hline & & $\mathrm{C}_{12}$ & 0.154 & 0.031 & 0.308 & 0.154 & 0.431 & 0.462 \\
\hline & & $\mathrm{C}_{13}$ & 0.334 & 0.668 & 1.001 & 0.334 & 0.334 & 0.668 \\
\hline & & $\mathrm{C}_{14}$ & 0.308 & 0.616 & 0.924 & 0.308 & 0.308 & 0.616 \\
\hline & & $\mathrm{C}_{15}$ & 0.385 & 0.128 & 0.770 & 0.128 & 0.770 & 0.385 \\
\hline & & $\mathrm{C}_{16}$ & 0.128 & 0.385 & 0.257 & 0.128 & 0.128 & 0.257 \\
\hline & & $\mathrm{C}_{17}$ & 0.283 & 0.424 & 0.989 & 0.283 & 0.057 & 0.791 \\
\hline & & $\mathrm{C}_{18}$ & 0.103 & 0.411 & 0.883 & 0.041 & 0.041 & 0.575 \\
\hline & \multirow{4}{*}{$\mathrm{B}_{4}$} & $\mathrm{C}_{19}$ & 0.526 & 0.526 & 2.104 & 0.263 & 0.263 & 1.578 \\
\hline & & $\mathrm{C}_{20}$ & 0.335 & 0.335 & 1.339 & 0.167 & 0.167 & 1.004 \\
\hline & & $\mathrm{C}_{21}$ & 0.335 & 0.335 & 1.339 & 0.167 & 0.167 & 1.004 \\
\hline & & $\mathrm{C}_{22}$ & 0.167 & 0.335 & 1.105 & 0.067 & 1.004 & 0.669 \\
\hline & \multirow{4}{*}{$\mathrm{B}_{5}$} & $\mathrm{C}_{23}$ & 0.198 & 0.594 & 1.782 & 0.198 & 0.198 & 0.990 \\
\hline & & $\mathrm{C}_{24}$ & 0.509 & 0.255 & 2.036 & 0.255 & 1.527 & 0.509 \\
\hline & & $\mathrm{C}_{25}$ & 1.782 & 0.509 & 0.764 & 0.255 & 1.018 & 0.764 \\
\hline & & $\mathrm{C}_{26}$ & 1.188 & 0.198 & 0.594 & 0.079 & 1.109 & 0.792 \\
\hline & \multirow{7}{*}{$\mathrm{B}_{6}$} & $\mathrm{C}_{27}$ & 0.241 & 0.120 & 0.963 & 0.120 & 0.241 & 0.722 \\
\hline & & $\mathrm{C}_{28}$ & 0.385 & 0.193 & 0.482 & 0.096 & 0.193 & 0.578 \\
\hline & & $\mathrm{C}_{29}$ & 0.722 & 0.482 & 1.926 & 0.241 & 0.482 & 0.963 \\
\hline & & $\mathrm{C}_{30}$ & 0.578 & 0.434 & 0.867 & 0.145 & 0.434 & 0.434 \\
\hline & & $\mathrm{C}_{31}$ & 1.084 & 0.434 & 1.517 & 0.434 & 0.217 & 0.650 \\
\hline & & $\mathrm{C}_{32}$ & 0.843 & 0.337 & 1.180 & 0.337 & 0.169 & 0.506 \\
\hline & & $\mathrm{C}_{33}$ & 0.771 & 0.193 & 1.541 & 0.385 & 0.771 & 0.193 \\
\hline
\end{tabular}

In order to ensure that the results obtained by using this method are reasonable and reliable, it is necessary to judge the consistency of the B-B judgment matrix, and use formula (22) to judge:

$$
C R=\frac{C I}{R I}<0.1 .
$$

Among them, $R I$ is the average random consistency index. The calculation formula of $C I$ is $C I=\left(\left(\lambda_{\max }-n\right) /(n-1)\right), n$ is the order of the judgment matrix, and the value of $R I$ is shown in Table 11.

In this example, $C I$ is 0.121 and $R I$ is 1.24 . Therefore, $C R$ is $0.098<0.1$, so it meets the consistency requirements.

The following is to find the judgment matrix of each factor of the indicator layer relative to the criterion layer, and the relative importance of each factor in the index layer to the criterion layer is calculated by pairwise comparisons, and the results are shown in Tables 12-17.

According to the calculation method of the weight eigenvectors of the evaluation factors of the criterion layer relative to the target layer, the weight vector of the $B_{1}-C$ judgment matrix is obtained, after calculation, $\lambda_{\max }=4.199, C I=0.066, R I=0.9$, and $C R=0.074<0.1$, which meets the consistency requirements. The weight vector occupied by $\mathrm{C}_{1}-\mathrm{C}_{4}$ is $w=(0.210,0.092,0.107$, $0.591)$.

The same calculation method is used to obtain the weight vector of the $\mathrm{B}_{2}-\mathrm{C}$ judgment matrix. After calculation, $\lambda_{\max }=5.406, C I=0.101, R I=1.12$, and $C R=0.091<0.1$, which satisfies the consistency requirements. The weight vector occupied by $\mathrm{C}_{5}-\mathrm{C}_{9} w$ is $(0.168,0.070,0.372,0.282$, 0.108 ).

Similarly, the weight vector of the $\mathrm{B}_{3}-\mathrm{C}$ judgment matrix is obtained by the above method. After calculation, $\lambda_{\max }=10.084, C I=0.136, R I=1.45, C R=0.093<0.1$, which satisfies the consistency requirements. The weight vector occupied by $\mathrm{C}_{10}-\mathrm{C}_{18}$ is $w=(0.042,0.075,0.036,0.288,0.218$, $0.108,0.029,0.144,0.06)$.

Similarly, obtain the weight vector of the $\mathrm{B}_{4}$ - $\mathrm{C}$ judgment matrix. After calculation, $\lambda_{\max }=4.215, C I=0.072, R I=0.9$, and $C R=0.08<0.1$, which meets the consistency requirements. The weight vector occupied by $\mathrm{C}_{19}-\mathrm{C}_{22}$ is $w=(0.410$, $0.151,0.321,0.118$ ).

Similarly, obtain the weight vector of the $\mathrm{B}_{5}$-C judgment matrix. After calculation, $\lambda_{\max }=4.222, C I=0.074, R I=0.9$, and $C R=0.082<0.1$, which meets the consistency requirements. The weight vector occupied by $\mathrm{C}_{23}-\mathrm{C}_{26}$ is $w=(0.079,0.424,0.340,0.156)$. 
TABle 8: Correlation coefficient matrix.

\begin{tabular}{|c|c|c|c|c|c|c|}
\hline$r 1$ & 1.000 & 0.835 & 0.775 & 0.794 & 0.713 & 0.638 \\
\hline$r 2$ & 0.692 & 0.759 & 0.361 & 1.000 & 0.455 & 0.744 \\
\hline$r 3$ & 0.341 & 0.488 & 0.365 & 1.000 & 0.390 & 0.587 \\
\hline$r 4$ & 0.382 & 0.948 & 0.673 & 1.000 & 0.784 & 0.773 \\
\hline$r 5$ & 0.512 & 0.999 & 0.480 & 0.833 & 0.368 & 0.406 \\
\hline$r 6$ & 0.341 & 0.621 & 0.395 & 1.000 & 0.421 & 0.410 \\
\hline$r 7$ & 0.501 & 0.413 & 0.766 & 0.725 & 0.900 & 0.999 \\
\hline$r 8$ & 0.424 & 0.349 & 1.001 & 0.613 & 0.761 & 0.549 \\
\hline$r 9$ & 0.717 & 0.394 & 0.929 & 1.000 & 0.802 & 0.601 \\
\hline$r 10$ & 0.587 & 0.360 & 0.895 & 0.873 & 0.489 & 1.000 \\
\hline$r 11$ & 1.000 & 0.593 & 0.886 & 0.858 & 0.379 & 0.597 \\
\hline$r 12$ & 0.615 & 0.713 & 0.962 & 1.000 & 0.681 & 0.625 \\
\hline$r 13$ & 0.397 & 0.461 & 0.646 & 0.645 & 0.484 & 0.999 \\
\hline$r 14$ & 0.397 & 0.461 & 0.646 & 0.645 & 0.484 & 0.999 \\
\hline$r 15$ & 0.496 & 0.509 & 0.569 & 1.000 & 0.345 & 0.620 \\
\hline$r 16$ & 0.507 & 0.371 & 0.719 & 0.740 & 0.594 & 0.999 \\
\hline$r 17$ & 0.622 & 1.001 & 0.676 & 0.937 & 0.496 & 0.704 \\
\hline$r 18$ & 0.479 & 0.677 & 0.453 & 1.000 & 0.480 & 0.672 \\
\hline$r 19$ & 0.405 & 0.902 & 0.342 & 1.000 & 0.367 & 0.411 \\
\hline$r 20$ & 0.405 & 0.902 & 0.342 & 1.000 & 0.367 & 0.411 \\
\hline$r 21$ & 0.405 & 0.902 & 0.342 & 1.000 & 0.367 & 0.411 \\
\hline$r 22$ & 0.375 & 0.999 & 0.576 & 0.808 & 0.462 & 0.992 \\
\hline$r 23$ & 0.385 & 0.728 & 0.340 & 1.000 & 0.435 & 0.631 \\
\hline$r 24$ & 0.405 & 0.566 & 0.342 & 1.000 & 0.398 & 0.466 \\
\hline$r 25$ & 0.343 & 0.895 & 0.412 & 1.000 & 0.824 & 0.654 \\
\hline$r 26$ & 0.450 & 0.556 & 0.404 & 0.745 & 0.418 & 0.999 \\
\hline$r 27$ & 0.405 & 0.566 & 0.342 & 1.000 & 0.484 & 0.411 \\
\hline$r 28$ & 0.833 & 0.874 & 0.998 & 1.000 & 0.415 & 0.345 \\
\hline$r 29$ & 0.552 & 0.902 & 0.342 & 1.000 & 0.484 & 0.895 \\
\hline$r 30$ & 0.692 & 0.407 & 0.361 & 1.000 & 0.455 & 0.411 \\
\hline$r 31$ & 0.745 & 0.999 & 0.466 & 0.670 & 0.384 & 0.726 \\
\hline$r 32$ & 0.745 & 0.999 & 0.466 & 0.670 & 0.384 & 0.726 \\
\hline$r 33$ & 1.000 & 0.652 & 0.394 & 0.717 & 0.961 & 0.410 \\
\hline
\end{tabular}
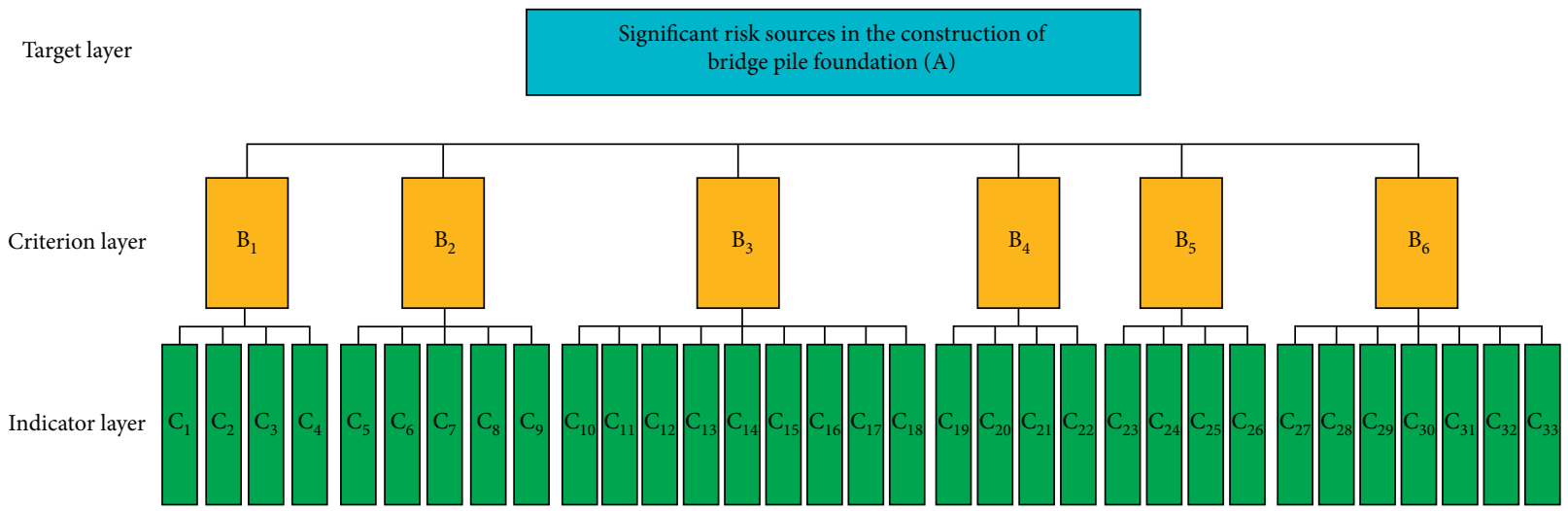

FIGURE 2: Hierarchical structure model for identifying major risk sources of pile foundation engineering of the Yinzhou Lake Bridge.

Table 9: Proportional scale table.

\begin{tabular}{lc}
\hline The relative importance of the $i$-th risk event to the $j$-th risk event & Quantized value \\
\hline Equally important & 1 \\
Slightly important & 3 \\
Stronger important & 5 \\
Strongly important & 7 \\
Extremely important & 9 \\
The middle value of two adjacent judgments & $2,4,6,8$ \\
\hline
\end{tabular}


TABle 10: A-B judgment matrix.

\begin{tabular}{ccccccc}
\hline $\mathrm{A}$ & $\mathrm{B}_{1}$ & $\mathrm{~B}_{2}$ & $\mathrm{~B}_{3}$ & $\mathrm{~B}_{4}$ & $\mathrm{~B}_{5}$ & $\mathrm{~B}_{6}$ \\
\hline $\mathrm{B}_{1}$ & 1 & 3 & $1 / 3$ & 5 & $1 / 3$ & $1 / 5$ \\
$\mathrm{~B}_{2}$ & $1 / 3$ & 1 & 7 & $1 / 3$ & $1 / 5$ & 9 \\
$\mathrm{~B}_{3}$ & 3 & 7 & 1 & 5 & 5 & $1 / 3$ \\
$\mathrm{~B}_{4}$ & $1 / 2$ & 3 & $1 / 5$ & 1 & $1 / 3$ & $1 / 7$ \\
$\mathrm{~B}_{5}$ & 3 & 5 & $1 / 5$ & 3 & 1 & $1 / 3$ \\
$\mathrm{~B}_{6}$ & 5 & 9 & 3 & 7 & 3 & 1 \\
\hline
\end{tabular}

Table 11: Average random consistency index.

\begin{tabular}{lcccccccc}
\hline 1 & 2 & 3 & 4 & 5 & 6 & 7 & 8 & 9 \\
\hline 0.00 & 0.00 & 0.58 & 0.9 & 1.12 & 1.24 & 1.32 & 1.41 & 1.45 \\
\hline
\end{tabular}

TABLE 12: $\mathrm{B}_{1}-\mathrm{C}$ judgment matrix.

\begin{tabular}{ccccc}
\hline $\mathrm{B}_{1}$ & $\mathrm{C}_{1}$ & $\mathrm{C}_{2}$ & $\mathrm{C}_{3}$ & $\mathrm{C}_{4}$ \\
\hline $\mathrm{C}_{1}$ & 1 & 3 & 3 & $1 / 3$ \\
$\mathrm{C}_{2}$ & $1 / 3$ & 1 & 3 & $1 / 9$ \\
$\mathrm{C}_{3}$ & $1 / 3$ & $1 / 3$ & 1 & $1 / 7$ \\
$\mathrm{C}_{4}$ & 3 & 9 & 7 & 1 \\
\hline
\end{tabular}

TABLE 13: $\mathrm{B}_{2}-\mathrm{C}$ judgment matrix.

\begin{tabular}{cccccc}
\hline $\mathrm{B}_{2}$ & $\mathrm{C}_{5}$ & $\mathrm{C}_{6}$ & $\mathrm{C}_{7}$ & $\mathrm{C}_{8}$ & $\mathrm{C}_{9}$ \\
\hline $\mathrm{C}_{5}$ & 1 & 3 & $1 / 3$ & $1 / 3$ & 3 \\
$\mathrm{C}_{6}$ & $1 / 3$ & 1 & $1 / 3$ & $1 / 3$ & $1 / 3$ \\
$\mathrm{C}_{7}$ & 3 & 3 & 1 & 2 & 3 \\
$\mathrm{C}_{8}$ & 3 & 3 & $1 / 2$ & 1 & 3 \\
$\mathrm{C}_{9}$ & $1 / 3$ & 3 & $1 / 3$ & $1 / 3$ & 1 \\
\hline
\end{tabular}

TABLE 14: $\mathrm{B}_{3}-\mathrm{C}$ judgment matrix.

\begin{tabular}{cccccccccc}
\hline $\mathrm{B}_{3}$ & $\mathrm{C}_{10}$ & $\mathrm{C}_{11}$ & $\mathrm{C}_{12}$ & $\mathrm{C}_{13}$ & $\mathrm{C}_{14}$ & $\mathrm{C}_{15}$ & $\mathrm{C}_{16}$ & $\mathrm{C}_{17}$ & $\mathrm{C}_{18}$ \\
\hline $\mathrm{C}_{10}$ & 1 & $1 / 3$ & 3 & $1 / 7$ & $1 / 5$ & $1 / 3$ & 2 & $1 / 3$ & $1 / 3$ \\
$\mathrm{C}_{11}$ & 3 & 1 & 3 & $1 / 3$ & $1 / 5$ & $1 / 3$ & 3 & $1 / 3$ & 2 \\
$\mathrm{C}_{12}$ & $1 / 3$ & $1 / 3$ & 1 & $1 / 5$ & $1 / 3$ & $1 / 5$ & 3 & $1 / 3$ & $1 / 3$ \\
$\mathrm{C}_{13}$ & 7 & 3 & 5 & 1 & 3 & 3 & 5 & 3 & 5 \\
$\mathrm{C}_{14}$ & 5 & 5 & 3 & $1 / 3$ & 1 & 3 & 5 & 3 & 5 \\
$\mathrm{C}_{15}$ & 3 & 3 & 5 & $1 / 3$ & $1 / 3$ & 1 & 3 & $1 / 3$ & 2 \\
$\mathrm{C}_{16}$ & $1 / 2$ & $1 / 3$ & $1 / 3$ & $1 / 5$ & $1 / 5$ & $1 / 3$ & 1 & $1 / 3$ & $1 / 3$ \\
$\mathrm{C}_{17}$ & 3 & 3 & 3 & $1 / 3$ & $1 / 3$ & 3 & 3 & 1 & 5 \\
$\mathrm{C}_{18}$ & 3 & $1 / 2$ & 3 & $1 / 5$ & $1 / 5$ & $1 / 2$ & 3 & $1 / 5$ & 1 \\
\hline
\end{tabular}

TABLE 15: $\mathrm{B}_{4}-\mathrm{C}$ judgment matrix.

\begin{tabular}{ccccc}
\hline $\mathrm{B}_{4}$ & $\mathrm{C}_{19}$ & $\mathrm{C}_{20}$ & $\mathrm{C}_{21}$ & $\mathrm{C}_{22}$ \\
\hline $\mathrm{C}_{19}$ & 1 & 3 & 2 & 2 \\
$\mathrm{C}_{20}$ & $1 / 3$ & 1 & $1 / 3$ & 2 \\
$\mathrm{C}_{21}$ & $1 / 2$ & 3 & 1 & 3 \\
$\mathrm{C}_{22}$ & $1 / 2$ & $1 / 2$ & $1 / 3$ & 1 \\
\hline
\end{tabular}

Similarly, obtain the weight vector of the $\mathrm{B}_{6}$-C judgment matrix. After calculation, $\lambda_{\max }=7.770, C I=0.128, R I=1.32$, and $C R=0.097<0.1$, which meets the consistency
TABLE 16: $\mathrm{B}_{5}-\mathrm{C}$ judgment matrix.

\begin{tabular}{lcccc}
\hline $\mathrm{B}_{5}$ & $\mathrm{C}_{23}$ & $\mathrm{C}_{24}$ & $\mathrm{C}_{25}$ & $\mathrm{C}_{26}$ \\
\hline $\mathrm{C}_{23}$ & 1 & $1 / 3$ & $1 / 5$ & $1 / 3$ \\
$\mathrm{C}_{24}$ & 3 & 1 & 2 & 3 \\
$\mathrm{C}_{25}$ & 5 & $1 / 2$ & 1 & 3 \\
$\mathrm{C}_{26}$ & 3 & $1 / 3$ & $1 / 3$ & 1 \\
\hline
\end{tabular}

TABLE 17: $\mathrm{B}_{6}-\mathrm{C}$ judgment matrix.

\begin{tabular}{lccccccc}
\hline $\mathrm{B}_{5}$ & $\mathrm{C}_{27}$ & $\mathrm{C}_{28}$ & $\mathrm{C}_{29}$ & $\mathrm{C}_{30}$ & $\mathrm{C}_{31}$ & $\mathrm{C}_{32}$ & $\mathrm{C}_{33}$ \\
\hline $\mathrm{C}_{27}$ & 1 & 3 & $1 / 7$ & $1 / 3$ & $1 / 5$ & $1 / 3$ & $1 / 5$ \\
$\mathrm{C}_{28}$ & $1 / 3$ & 1 & $1 / 7$ & $1 / 5$ & $1 / 7$ & $1 / 7$ & $1 / 7$ \\
$\mathrm{C}_{29}$ & 7 & 7 & 1 & 5 & 3 & 5 & 3 \\
$\mathrm{C}_{30}$ & 3 & 5 & $1 / 5$ & 1 & $1 / 5$ & $1 / 3$ & $1 / 5$ \\
$\mathrm{C}_{31}$ & 5 & 7 & $1 / 3$ & 5 & 1 & 5 & 3 \\
$\mathrm{C}_{32}$ & 3 & 7 & $1 / 5$ & 3 & $1 / 5$ & 1 & $1 / 3$ \\
$\mathrm{C}_{33}$ & 5 & 7 & $1 / 3$ & 5 & $1 / 3$ & 3 & 1 \\
\hline
\end{tabular}

requirements. The weight vector occupied by $\mathrm{C}_{27}-\mathrm{C}_{33}$ is $w=(0.039,0.021,0.362,0.060,0.252,0.093,0.171)$.

4.4.3. Calculating the Combination Weights and the Total Ranking. The combined weight of each risk source is the product of the weight of each risk source in the indicator layer and the weight eigenvector of the indicator layer. The results are as follows:

(1) The weight of each risk source for equipment transportation and installation event is $0.094 \times(0.210,0.092,0.107,0.591)=(0.020,0.009$, $0.010,0.056)$.

(2) The weight of each risk source of the burying of protective cylinders incident is $0.03 \times(0.168,0.070$, $0.372,0.282,0.108)=(0.005,0.002,0.011,0.008$, 0.003).

(3) The weight of each risk source of the drilling holes event is $0.267 \times(0.042,0.075,0.036,0.288,0.218$, $0.108,0.029,0.144,0.06)=(0.011,0.020,0.010,0.077$, $0.058,0.029,0.008,0.038,0.016)$.

(4) The weight of each risk source of the cleaning hole event is $0.048 \times(0.410,0.151,0.321,0.118)=(0.020$, $0.007,0.015,0.006$ ).

(5) The weight of each risk source in the event of lifting of steel cages is $0.136 \times(0.079,0.424,0.340$, $0.156)=(0.011,0.058,0.046,0.02)$.

(6) The weight of each risk source of pouring underwater concrete event is $0.425 \times(0.039,0.021,0.362,0.06$, $0.252,0.093,0.171)=(0.017,0.009,0.154,0.026$, $0.107,0.040,0.073)$.

In summary, according to the calculated weights of each risk source index, sorting from large to small, the overall ranking results of all risk factors faced by the bridge during the construction process are $\mathrm{C}_{29}, \mathrm{C}_{31}, \mathrm{C}_{13}, \mathrm{C}_{33}, \mathrm{C}_{14}, \mathrm{C}_{24}, \mathrm{C}_{4}$, $\mathrm{C}_{25}, \mathrm{C}_{32}, \mathrm{C}_{17}, \mathrm{C}_{15}, \mathrm{C}_{30}, \mathrm{C}_{26}, \mathrm{C}_{11}, \mathrm{C}_{1}, \mathrm{C}_{19}, \mathrm{C}_{27}, \mathrm{C}_{18}, \mathrm{C}_{21}, \mathrm{C}_{10}, \mathrm{C}_{7}$, $\mathrm{C}_{23}, \mathrm{C}_{3}, \mathrm{C}_{12}, \mathrm{C}_{28}, \mathrm{C}_{2}, \mathrm{C}_{8}, \mathrm{C}_{16}, \mathrm{C}_{20}, \mathrm{C}_{22}, \mathrm{C}_{5}, \mathrm{C}_{9}, \mathrm{C}_{6}$. The major 
risk sources include pipe stuck $\left(\mathrm{C}_{29}\right)$, broken piles $\left(\mathrm{C}_{31}\right)$, plum blossom holes $\left(\mathrm{C}_{13}\right)$, leakage and deviation of reinforcement skeleton $\left(\mathrm{C}_{33}\right)$, drilling rig shift $\left(\mathrm{C}_{14}\right)$, the skeleton collides with the hole wall when lifting $\left(\mathrm{C}_{24}\right)$, unstable construction platform $\left(\mathrm{C}_{4}\right)$, unqualified welding quality $\left(\mathrm{C}_{25}\right)$, pile body concrete enters mud $\left(\mathrm{C}_{32}\right)$, drilling rig malfunctions $\left(\mathrm{C}_{17}\right)$, reaming or shrinking holes $\left(\mathrm{C}_{15}\right)$, buried pipes $\left(\mathrm{C}_{30}\right)$, unsuitable frame elevation $\left(\mathrm{C}_{26}\right)$, bore hole tilt $\left(\mathrm{C}_{11}\right)$, drill rack installation tilt $\left(\mathrm{C}_{1}\right)$, etc.

Comparing the GECA method and the AHP method in the study of identifying the significant risk sources during bridge construction period, it can be seen that both use the expert scoring method to determine the relative importance of the risk sources. However, in the preliminary identification of risk sources, this paper uses the F-AHP, which reduces the consistency test compared with the AHP, and is simple to calculate in the process of determining the weights, and only requires the establishment of a comparison matrix between two, without the need for a complex calculation process, which is convenient for decision-makers to operate. The method proposed in this paper takes into account the inherent correlation between risk sources and gives consideration to the possibility that a risk source may induce the occurrence of other risks when it occurs, which is more comprehensive, scientific, and reasonable.

\section{Conclusion and Future Work}

There are many risk factors during the construction period of large and complex bridges. In the process of risk identification, the interaction and internal relationship among all kinds of risk factors are often ignored, the dynamic risk sources in the construction process are often insufficiently considered, and the weight assignment of risk indicators is often maximized to consider human subjective factors. In order to more scientifically and reasonably identify the risk factors that exist during the bridge construction period and identify the major safety risk sources during the bridge construction process, a study on the identification of significant risk sources during the bridge construction period based on the GECA method was carried out. The main conclusions are as follows:

(1) Combining the occurrence characteristics, interaction, and transmission mechanisms of safety risks during bridge construction, a method combining qualitative and quantitative approaches is proposed. The expert scoring method is used to establish a fuzzy consistent judgment matrix, and then the F-AHP is used to quantify the risk, which is simple, practical, and highly accurate, and can avoid the influence of human subjective factors on risk quantification to a greater extent.

(2) F-AHP is used as a risk source identification tool to assign the initial weight values of risks. By this fuzzy method, the influence of human factors on the GECA model can be greatly reduced.

(3) Apply grey theory and EW to identify significant risk sources by analyzing the internal correlation of each risk source, grasping its development rules and characteristics, applying the grey relevance analysis method to establish the correlation matrix, then using the EW idea to establish the weight of various risk sources and rank them, and using this method as the judgment criteria for the identification of significant risk sources.

(4) On the basis of the above theoretical study, fully consider the construction characteristics and construction management level of the Zhongkai Expressway Yinzhou Lake Bridge to conduct application research to verify the correctness and applicability of theories, methods, and models, and to provide a basis for the identification of significant risk sources during the bridge construction period.

This paper provides a new method of identifying significant risk sources applicable to the bridge construction period. However, this paper still has certain limitations. First of all, this method is a comprehensive application of several methods, and complexity is its distinctive feature. The application of this method requires some mathematical knowledge and engineering experience. Secondly, for some large and complex bridges, there are also many risk sources during the design and operation periods. Therefore, it is necessary to verify whether these methods are equally applicable in different engineering projects, so as to have a more comprehensive understanding of various risk source factors of bridges in different stage.

Nowadays, decision-makers in the process of bridge construction generally prefer to rely on their professional experience to determine the source of risk. However, it should be noted that China's development speed is getting faster and faster, and the constructed bridges are moving toward large-span, light-weight, intelligent, etc. The construction of bridges is becoming increasingly complex, which is difficult to accommodate by common methods and requires some innovation. This paper takes an example of a super bridge to carry out theoretical research work to satisfy the reliability of the bridge itself. Although the calculation of this method may be complicated, it effectively considers the inherent correlation between risk source factors and reduces the interference of subjective factors in the weight determination process. Next, we are studying the data visualization system for bridge construction risk sources, and we only need to input relevant numbers to obtain the significant risk sources, and we are confident that we can use programming languages to edit complex formulas into programs, thus simplifying the calculation process and producing simple and beautiful results on the system.

\section{Data Availability}

The data used to support the findings of this study are included within the manuscript.

\section{Conflicts of Interest}

The authors declare no conflicts of interest. 


\section{Authors' Contributions}

The authors have read and agreed to the published version of the manuscript.

\section{Supplementary Materials}

Table $\mathrm{S} 1: \mathrm{B}_{1}-\mathrm{C}_{1-4}$ relationship matrix. Table $\mathrm{S} 2$ : $\mathrm{B}_{2}-\mathrm{C}_{5-9}$ relationship matrix. Table $\mathrm{S} 3: \mathrm{B}_{3}-\mathrm{C}_{10-18}$ relationship matrix. Table S4: $B_{4}-C_{19-22}$ relationship matrix. Table $S 5: B_{5}-C_{23-26}$ relationship matrix. Table $\mathrm{S} 6: \mathrm{B}_{6}-\mathrm{C}_{27-33}$ relationship matrix. Table S7: $\mathrm{B}_{1}-\mathrm{C}_{1-4}$ fuzzy consistent matrix $R$ and relative weight value $w_{B}^{C}$. Table S8: $\mathrm{B}_{2}-\mathrm{C}_{5-9}$ fuzzy consistent matrix $R$ and relative weight value $w_{B}^{C}$. Table $S 9: B_{3}-C_{10-18}$ fuzzy consistent matrix $R$ and relative weight value $w_{B}^{C}$. Table S10: $\mathrm{B}_{4}-\mathrm{C}_{19-22}$ fuzzy consistent matrix $R$ and relative weight value $w_{B}^{C}$. Table S11: $\mathrm{B}_{5}-\mathrm{C}_{23-26}$ fuzzy consistent matrix $R$ and relative weight value $w_{B}^{C}$. Table $S 12: \mathrm{B}_{6}-\mathrm{C}_{27-33}$ fuzzy consistent matrix $R$ and relative weight value $w_{B}^{C}$. (Supplementary Materials)

\section{References}

[1] L. Wang, "The risk assessment and management of bridge construction," Journal of Chengdu Technological University, vol. 4, pp. 12-14, 2016, in Chinese.

[2] I. Mahamid, "Risk matrix for factors affecting time delay in road construction projects: owners' perspective," Engineering, Construction and Architectural Management, vol. 18, no. 6, pp. 609-617, 2011.

[3] X. Ruan, Risk Assessment System and Key Issues for Bridge Engineering, Tongji University, London, UK, 2006, in Chinese.

[4] S. Seyed, "“Risk identification in the early design stage using thermal simulations-a case study," Sustainability, vol. 10, no. 1, p. 262, 2018

[5] Z. G. Wu, R. J. Shen, F. M. Wan et al., "A method for identifying operation safety risk source of rocky high slope," Journal of Highway and Transportation Research and Development, vol. 35, no. 3, pp. 8-15, 2018, in Chinese.

[6] Z. J. Liang, C. Wang, and F. C. Jiang, "Identification of risk sources of ship pilotage based on Delphi method and prehazard analysis," Port Economy, vol. 23, no. 3, pp. 58-60, 2017, in Chinese.

[7] M. Ahmadi and K. Behzadian, "Comprehensive risk management using fuzzy FMEA and MCDA techniques in highway construction project," Journal of Civil Engineering and Management, vol. 23, no. 2, pp. 300-310, 2017.

[8] T. L. Saaty, Group Decision Making and the AHP, Springer, Berlin, Germany, 1989.

[9] L. S. Bao and K. T. Liu, "Multi-objective risk analysis and documents assessment of bridge construction based on AHPGRAY," Journal of Shenyang Jianzhu University (Natural Science), vol. 25, no. 4, pp. 663-669, 2009, in Chinese.

[10] Y.-M. Wang, J. Liu, and T. M. S. Elhag, "An integrated AHPDEA methodology for bridge risk assessment," Computers \& Industrial Engineering, vol. 54, no. 3, pp. 513-525, 2008.

[11] J. Wang, Y. Yin, and H. Wu, "Critical safety risks identification of bridge construction projects in the marine environment based on HHM and SNA," Computers \& Industrial Engineering, vol. 108, no. 1, pp. 48-52, 2020.

[12] F. Q. Wang and J. L. Huang, "Risk assessment of construction safety of high-speed railway bridge across existing lines based on BP neural network," Journal of Railway Science and Engineering, vol. 16, no. 5, pp. 1129-1136, 2019, in Chinese.

[13] X. D. Zhang, J. F. Guo, J. Y. Yu et al., "Risk identification in construction of mountainous high-rise pier and long span continuous rigid-frame bridges," Bridge Construction, vol. 6, pp. 80-83, 2008, in Chinese.

[14] X. H. Ouyang, Z. Y. Li, Z. E. Zheng et al., "Comprehensive identification and assessment method of bridge construction risk," Highway Engineering, vol. 38, no. 5, pp. 30-33, 2013, in Chinese.

[15] Z. Shi and D. D. Liu, "Assessment of construction risk for super-large open caisson foundation based on WBS-RBS," Railway Engineering, vol. 60, no. 8, pp. 37-42, 2020, in Chinese.

[16] T. Zayed, R. E. Minchin, and A. J. Boyd, "Model for the physical risk assessment of bridges with unknown foundation," Journal of Performance of Constructed Facilities, vol. 21, no. 1, pp. 44-52, 2007.

[17] Q. F. Smith, P. Cong, H. T. Yang, and H. F. Li, "Application of AHP based on entropy weight for risk identification in bridge construction," Advanced Materials Research, vol. 243-249, pp. 1871-1875, 2011.

[18] Q.-F. Li, P. Zhang, and Y.-C. Fu, "Risk identification for the construction phases of the large bridge based on WBS-RBS," Research Journal of Applied Sciences, Engineering and Technology, vol. 6, no. 9, pp. 1523-1530, 2013.

[19] Y. Q. Xiang, Q. Q. Wu, and T. T. Zhang, "Research on risk assessment of bridge design based on AHP-FCE model," China Civil Engineering Journal, vol. 43, no. 2, pp. 275-280, 2010.

[20] J. Zhang, Study on Risk Analysis Method of Long-Span Bridge during Construction, Tongji University, London, UK, 2007, in Chinese.

[21] X. L. Liu, "Research on the development strategy of structural engineering in my country," Tsinghua Journal of Education, vol. 2, pp. 48-52, 1992, in Chinese.

[22] P. Liu, H. Yang, and Y. R. Hu, "Three-way decisions with single-valued neutrosophic decision theory rough sets based on grey relational analysis," Mathematical Problems in Engineering, vol. 2019, pp. 1-12, 2019.

[23] J. Shi, Z. Ding, W.-J. Lee, Y. Yang, Y. Liu, and M. Zhang, "Hybrid forecasting model for very-short term wind power forecasting based on grey relational analysis and wind speed distribution features," IEEE Transactions on Smart Grid, vol. 5, no. 1, pp. 521-526, 2014.

[24] H. Liu, Y. Dong, F. Wang et al., "Gas outburst prediction model using improved entropy weight grey correlation analysis and IPSO-LSSVM," Mathematical Problems in Engineering, vol. 2020, pp. 1-10, 2020.

[25] W. Gong, N. Wang, N. Zhang et al., "Water resistance and a comprehensive evaluation model of magnesium oxychloride cement concrete based on Taguchi and entropy weight method," Construction and Building Materials, vol. 260, 2020.

[26] M. Y. Liu and K. M. Jin, "Set pair analysis for construction risk assessment of long span suspension bridge," Journal of Civil Engineering and Management, vol. 34, no. 5, pp. 5-7, 2017, in Chinese.

[27] J. Yang, Research on Risk Assessment of Cross-Sea Bridge Construction, Chongqing Jiaotong University, London, UK, 2015, in Chinese.

[28] K. K. Peng, F. N.. Catbas, and Z. Y. Wan, "Research on comprehensive safety risk assessment method for bridge engineering design," Journal of East China Jiaotong University, vol. 30, no. 4, pp. 7-13, 2013, in Chinese. 
[29] L. Wu and Z. Xia, "Research on optimal selection and evaluation methods of pile foundation scheme based on fuzzy analytic hierarchy process," Urban Roads Bridges \& Flood Control, vol. 8, pp. 88-90, 2018, in Chinese.

[30] Q. Li, Fuzzy Evaluation of Patent Quality Hesitant Based on Intuitionistic Fuzzy Analytic Hierarchy Process, Zhengzhou Institute of Aeronautical Industry Management, London, UK, 2019, in Chinese.

[31] Y. X. Xue, Risk Identification Techniques in Construction Period of Major Bridge and the Study on Risk Handling, Zhengzhou University, London, UK, 2011, in Chinese.

[32] Q. H. Zeng and Z. Y. Luo, "Risk identification study based on the grey relation of bridge construction period," Highway Engineering, vol. 37, no. 6, pp. 29-32, 2012, in Chinese.

[33] X. W. Sun, "System analysis and application research of bridge risk assessment methods," Highway Transportation Science and Technology (Applied Technology Edition), vol. 10, no. 9, pp. 223-227, 2014, in Chinese.

[34] W. Q. Li, "Research on the application of grey correlation theory in comprehensive evaluation of bridge adaptability," China Water Transport, vol. 16, no. 4, pp. 199-202, 2016, in Chinese.

[35] J. Zhang, N. N. Zhou, and P. F. Ding, "Comprehensive performance evaluation of AUV based on gray fuzzy," Journal of Anhui University of Science and Technology (Natural Science), vol. 39, no. 4, pp. 1-5, 2019, in Chinese.

[36] J. Jin, Research on the Value Evaluation of Information Entropy in the Big Data Era, Jilin University, London, UK, 2019, in Chinese.

[37] X. Lin, Risk Management Research on Entropy Measurement of Foundation Pit Engineering Project, Chongqing University, London, UK, 2006, in Chinese.

[38] Ministry of Transport of the People's Republic of China, Guidelines for Safety Risk Assessment of Highway Bridge and Tunnel Engineering Construction (Trial), Ministry of Transport of the People's Republic of China, Beijing, China, 2011.

[39] J. X. Xun, B. You, and S. L. Shi, "Risk identification and evaluation analysis of bridge construction based on Analytic Hierarchy Process," Mining Engineering Research, vol. 35, no. 1, pp. 59-64, 2020, in Chinese.

[40] X. J. Long, "Risk identification during the construction of high-pier and long-span bridges in mountainous areas," Heilongjiang Transportation Science and Technology, vol. 40, no. 6, pp. 139-140, 2017, in Chinese. 